\title{
Al-La-Sb (Aluminum-Lanthanum-Antimony)
}

\section{Raghavan}

Recently, [2010Che] determined an isothermal section for this ternary system at $500{ }^{\circ} \mathrm{C}$, which depicts no ternary compounds.

\section{Binary Systems}

The Al-La system [2006Zho, 2010Che, Massalski2] depicts the following intermetallic compounds: $\mathrm{La}_{3} \mathrm{Al}$ ( $L 1_{2}, \mathrm{AuCu}_{3}$-type cubic), $\mathrm{La}_{2} \mathrm{Al}$ (tetragonal, lattice parameters $a=1.70942 \mathrm{~nm}$ and $c=0.53790 \mathrm{~nm}$ [2010Che]), $\mathrm{La}_{5} \mathrm{Al}_{4}\left(\mathrm{La}_{5} \mathrm{Al}_{4}\right.$-type hexagonal, space group $\left.P 62 m\right), \mathrm{LaAl}$ (AlCe-type orthorhombic), $\mathrm{LaAl}_{2}\left(C 15, \mathrm{MgCu}_{2}\right.$-type cubic), $\mathrm{LaAl}_{3} \quad\left(D 0_{19}, \mathrm{Ni}_{3} \mathrm{Sn}\right.$-type hexagonal $)$ and $\beta \mathrm{La}_{3} \mathrm{Al}_{11}$ $\left(D 1_{3}, \mathrm{Al}_{4} \mathrm{Ba}\right.$-type tetragonal) and $\alpha \mathrm{La}_{3} \mathrm{Al}_{11}\left(\mathrm{La}_{3} \mathrm{Al}_{11}\right.$-type orthorhombic). The Al-Sb phase diagram [Massalski2] depicts the stoichiometric compound AlSb (B3, sphaleritetype cubic). The La-Sb system [2010Che] has the following intermediate compounds: $\mathrm{La}_{2} \mathrm{Sb}$ ( $\mathrm{La}_{2} \mathrm{Sb}$-type tetragonal), $\mathrm{La}_{5} \mathrm{Sb}_{3}\left(D 8_{8}, \mathrm{Mn}_{5} \mathrm{Si}_{3}\right.$-type hexagonal), $\mathrm{La}_{4} \mathrm{Sb}_{3}\left(D 7_{3}, \mathrm{P}_{4} \mathrm{Th}_{3}\right.$ type cubic), and $\mathrm{LaSb}$ (NaCl-type cubic).

\section{Ternary Isothermal Section}

With starting metals of $99.95 \% \mathrm{Al}, 99.5 \% \mathrm{La}$ and $99.9 \%$ $\mathrm{Sb}$, [2010Che] arc-melted under Ar atm a number of binary and ternary alloys. The samples were annealed at $500{ }^{\circ} \mathrm{C}$ for $30 \mathrm{~d}$ and quenched in liquid nitrogen. The phase equilibria were studied with $\mathrm{x}$-ray powder diffraction and scanning electron microscope equipped with energy dispersive x-ray analyzer. The isothermal section at $500{ }^{\circ} \mathrm{C}$ constructed by [2010Che] is shown in Fig. 1. There are no ternary phases. The solubility of the third component in the binary compounds is negligible.

\section{References}

2006Zho: S.H. Zhou and R.E. Napolitano, Phase Equilibria and Thermodynamic Limits for Partitionless Crystallization in the Al-La Binary System, Acta Mater., 2006, 54, p 831-840

2010Che: Y. Chen, Q. Feng, L. Zeng, J. He, and W. He, Phase Relationships of the La-Al-Sb System at $773 \mathrm{~K}$ from 0 to 50.0 at.\% Sb, J. Alloys Compd., 2010, 492, p 208-212

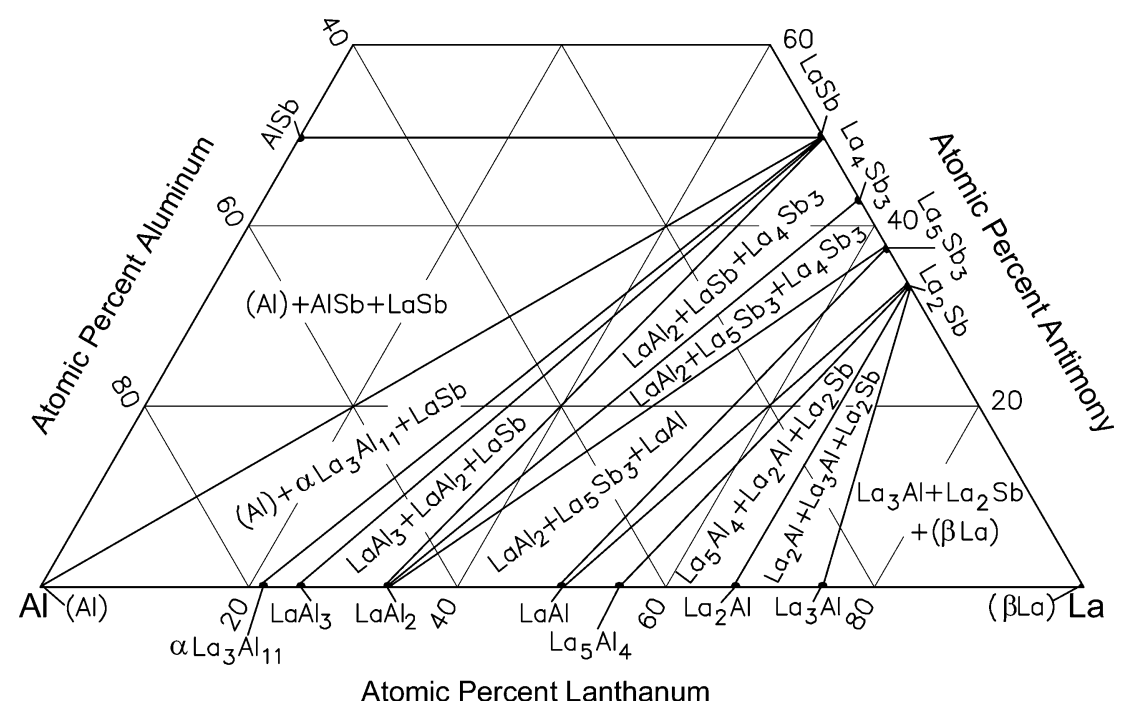

Fig. 1 Al-La-Sb isothermal section at $500{ }^{\circ} \mathrm{C}$ [2010Che]. Narrow two-phase regions are omitted 